\title{
Research on the Optimal Path of Practice Teaching in Teacher Education
}

\author{
Xiaohe Wang \\ Pingdingshan College, Pingdingshan, Henan, China
}

\begin{abstract}
The teacher education major is a highly practical major, and practical teaching is an important curriculum area of the teacher education major, which plays an important role in improving the professional practical ability of students. At present, although many universities pay more and more attention to practical teaching, there are still certain problems in the process of ideological understanding and actual implementation. To optimize practical teaching, it is necessary to recognize the factors that affect practical teaching and the role of each factor in talent training, and put forward optimization paths and measures based on the establishment of collaborative cooperation mechanism, construction of teaching staff, and formulation of practice manuals.
\end{abstract}

Key words: teacher education; practical teaching; effectiveness

\section{Introduction}

With the implementation of the Excellent Teacher Program, colleges and universities pay more and more attention to the training of normal students, and regard practical teaching as an important part of the reform of teacher education. The Teacher Education Curriculum Standard (Trial) clearly stated that the time for teacher education professional education practice should not be less than 18 weeks. As a result, various universities have also extended the time for practical teaching. However, due to differences in concepts, faculty, equipment, system and mechanism construction among universities, there are some problems in practical teaching, which restrict the value of practical teaching.

\section{The Status Quo of Practical Teaching in Teacher Education}

There are two main methods for pre-employment training for primary and secondary school teachers. One is the teacher education major at the school of educational science; the other is the major attributable to different schools, such as the English education major of the school of foreign languages, mathematics education in the school of mathematical sciences. Relatively speaking, the academy of educational sciences is a department that specializes in cultivating teachers, which arrangements for the practical teaching system are systematic. The focus of teacher professional development in other departments is not on teacher training. Therefore, the human and material resources invested in the design and arrangement of practical teaching are relatively small, and practical teaching is not optimistic. At present, there are the following problems in the practical teaching of college teacher education.

2.1 The cooperative relationship between universities and primary and secondary schools is not deep enough

"University is a place for theoretical study, while primary and secondary schools are the basis for teachers' practice. Only by realizing the cooperation of the two can we effectively shorten the distance between future teachers' theory and 
practice."

The improvement of students' practical ability requires continuous contact with the actual field of primary and secondary schools and their support. Due to the unevenness of normal universities in our country, the way of cooperation between primary and secondary schools has also encountered different problems. Provincial and ministerial-level teachers' colleges have an advantageous position in terms of teachers, hardware, and concepts. Relatively speaking, the cooperation between colleges and primary schools is relatively smooth. However, local colleges and universities are relatively disadvantaged in terms of teachers, equipment, funds, and concepts. They have not found a suitable link of interests in the process of cooperation with primary and secondary schools. The cooperation between universities is relatively passive and cannot reach the level of cooperation with primary and secondary schools. Win-win cooperation directly affects the continuity and depth of cooperation.

2.2 Inadequate guidance for the teaching staff of practical teaching and lack of substantive guidance for students' practical teaching

An important factor affecting the effectiveness of educational internships is the guidance of intern instructors. "One of the reasons for the failure of some internship programs is because there are no qualified intern instructors." The United States is a country that places great emphasis on educational practice. In the pre-employment training of elementary and middle school teachers, educational practice is a necessary condition for the next stage of learning. Only students who pass the assessment in the educational practice can enter the next stage of learning, otherwise they will repeat the internship. Of course, not all educational internships have achieved the expected results. Special investigations have shown that among the factors that hinder the success of normal students, the number one instructor is the lack of good internship instructors. In China, the internship guidance for normal students is mainly composed of instructors from colleges and universities and instructors from primary and secondary schools. As far as the faculty of teacher education in colleges and universities is concerned, most of them are graduate students from higher education institutions. They have a common problem that they lack basic education and teaching experience, and they have no knowledge, abilities and attitudes that teachers in primary and secondary schools should know. Such a team of teachers lacks a certain practical guidance ability, and practice guidance is more of a form, while substantive guidance is scarce, which seriously affects the practical effect.

2.3 The evaluation of practical teaching is simple and casual, lacking a corresponding practical teaching evaluation system

At present, there are simplification and randomness in the evaluation of the practical teaching of normal students, and there is a lack of scientific and systematic management. The simplification is embodied in the fact that the instructor's evaluation of interns is only limited to listening to one class and filling out the appraisal form for internship. The arbitrariness is reflected in the fact that most teachers do not pay attention to the evaluation of students' internship performance, lack objectivity in assessing students' performance, and show "high scores" and ghostwriting by students. As a result, it is difficult for students to use assessment to truly reflect whether students are absent, their level of practical ability and their specific performance, and evaluation loses its own value, leading to wrong attitudes, lack of motivation, and low enthusiasm for students' internships. The main reason for the randomness and simplification of evaluation lies in the lack of scientific and systematic management of course evaluation and internship evaluation in universities. Practical teaching evaluation involves the investigation of the comprehensive quality of students in many aspects, which requires teachers to spend a lot of time and energy. However, the school has not carried out corresponding monitoring of teachers' guidance and has not given corresponding compensation, which directly affects teachers' guidance behavior. 


\section{The System Design of Practice Teaching of Teacher Education}

To solve the problems in practical teaching and improve the status quo of practical teaching in teacher education, we need to correctly understand the effectiveness of practical teaching and use it as a reference for our improvement. According to the meaning of effectiveness, the effectiveness, benefit and efficiency of practical teaching are defined in three aspects. Effective practical teaching must be efficient on the premise that it is effective and profitable. There are many factors that affect practical teaching, in order to improve practical teaching, these factors must be considered. The role and status in training, the relationship between various factors, and the status and role of various factors in talent training are shown in Figure 1.

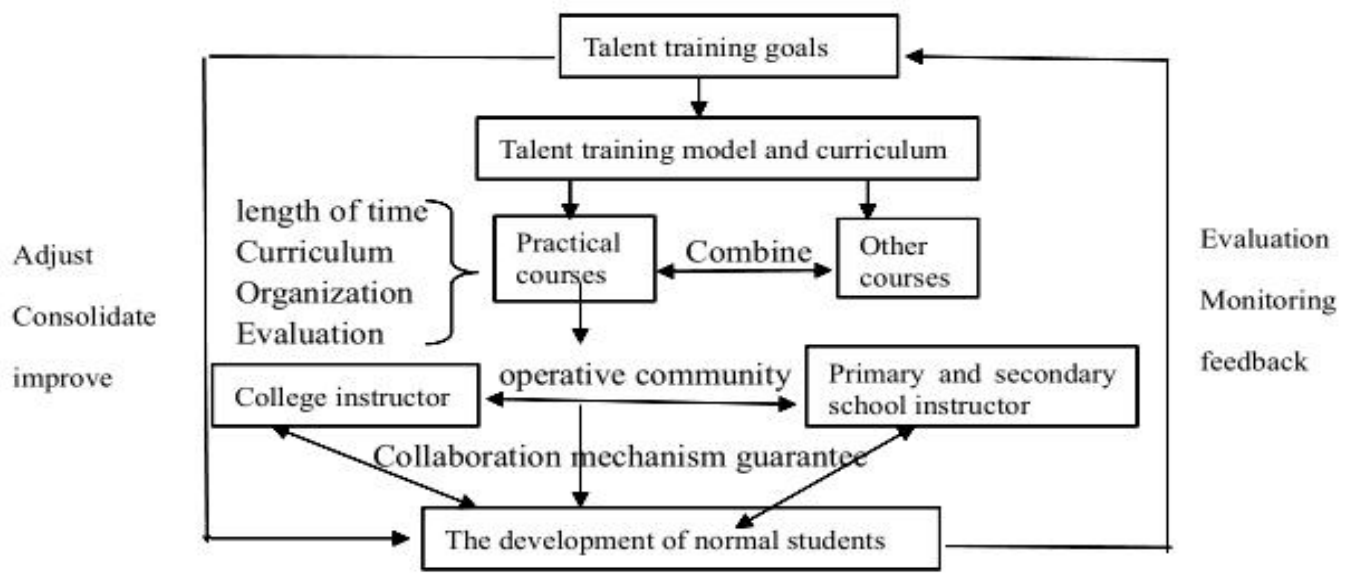

Finger 1. Schematic diagram of teaching system

It can be seen from Figure 1 that there are complex relationships among various factors in practical teaching. Therefore, to optimize the professional practice teaching of teacher education, it is necessary to consider the status and role of multiple internal and external factors in the improvement of the teaching practice ability of normal students, including the design of the practice teaching system, the reform of the talent training model, the construction of the practice guidance team, the university cooperative relationship with primary and secondary schools, and the evaluation of practical teaching and other factors, in order to construct an effective practical teaching system.

\section{4. the Realization Path of Effective Practical Teaching of Teacher Education in Colleges and}

\section{Universities}

From the perspective of internal and external factors, practical teaching is an interrelated system. Optimizing practical teaching requires comprehensive consideration of the status and role of various factors in the training of normal students from the perspective of system theory, and systematic reform and optimization. This includes not only conceptual updates, but also intermediate-level program design, which of course depends on implementation-level measures and specific behaviors.

4.1 Enhance the practical guidance ability of college teachers

It is necessary to clarify the responsibilities and tasks of college instructors. Many college teachers are not clear about their tasks in the education practice guidance, and their understanding of the purpose and content of the education practice is not accurate. They simply think that the instructor is going to the practice range to a lesson and then fill out the practice appraisal form. Therefore, colleges and universities must issue corresponding documents to clarify the responsibilities and tasks of internship instructors, and attach importance to the monitoring of internship guidance for normal students. Secondly, it is necessary to strengthen the training of instructors in colleges and universities to improve their practical ability. The reason why college instructors lack substantive guidance is that on the one hand, the sense of responsibility is 
not in place; on the other hand, the practical reason is the lack of practical experience. As the main undertakers of practical guidance for normal students, college teachers must understand the professional characteristics of primary and secondary school teachers and be familiar with the work field of primary and secondary school teachers. To improve the practical guidance ability of college instructors, schools should formulate corresponding policies to improve teachers' practical ability, and provide corresponding funds to encourage college teachers to enter primary and secondary schools to participate in practice.

4.2 Strengthen the coordination and cooperation between universities and primary and secondary schools

First, give play to the government's synergistic role in the collaboration of universities and primary and secondary schools to provide institutional and policy guarantees for collaboration. Second, universities and primary and secondary schools should clarify the interests of both parties in coordination and cooperation, achieve mutual benefit and win-win results, and form an internal driving force for cooperation. Colleges and universities should actively optimize their own resources and reflect their value and advantages in serving the development of primary and secondary schools. Only in this way can they achieve a win-win cooperation and a best-selling mechanism, so that the cooperation can be deep and continuous.

4.3 Compile the corresponding instruction manual for educational practice

Many teachers and interns are not clear about what they want to do in the internship process. The main reason is the lack of corresponding internship instruction manual. Even if there is an internship manual, it is out of practice and lacks professional guidance which can guide students and teachers. In contrast, the educational practice instruction manual in the United States is more instructive and maneuverable, which introduces the different stages of internship in detail, and puts forward corresponding requirements and assessment standards. Therefore, to optimize practical teaching, it is necessary to compile a highly operable instruction manual that combines theory and practice to clarify the concept of educational practice, the purpose, tasks, and content of educational practice, as well as the teaching practice, which primary and secondary school teachers should have ability to propose corresponding specific requirements, presented in the form of forms, questionnaires, etc. In this way, on the one hand, it is helpful for interns to clarify the purpose and content of the internship; on the other hand, it can provide students with professional internship guidance to solve the problems they encounter before and during the internship.

4.4 Establish a practical teaching evaluation system based on the professional standards of primary and secondary school teachers, and strengthen quality monitoring

Evaluation is a key part of practical teaching, which is guided by students' practical behavior and instructors. The Opinions on Strengthening the Practice of Teacher Education issued by the Ministry of Education pointed out that the institutions that conduct teacher education should focus on the evaluation of instructors, taking into account peer evaluation, self-evaluation, student evaluation and practice base evaluation, and comprehensively use classroom observation and student interviews and diversified methods such as the analysis of educational practice files, and comprehensively and objectively evaluate the educational practice of normal students. In terms of educational practice, the subject of evaluation should include interns, college instructors, and primary and secondary school instructors. From the perspective of evaluation tools, each evaluation tool is a means of organizing courses and teaching, and evaluating the development of pre-service teachers. No matter whether this organization is within or between courses, there is no tool that can present teaching. Therefore, multiple evaluation tools can be used comprehensively. Evaluation methods such as performance evaluation, portfolio evaluation, case studies, work analysis, and simulation can be applied to the evaluation of different abilities. 


\section{Conclusions}

Practical teaching alone cannot improve the effect of practical teaching. It is necessary to incorporate practical teaching into the whole system of talent training from the perspective of system theory, comprehensively consider the relationship between various factors, and carry out reforms and efforts in many aspects. In order to improve the effectiveness of practical teaching, in addition to the above-mentioned efforts, it is also necessary to strengthen the sense of responsibility of colleges and universities for talent training, and to avoid blindly expanding enrollment in pursuit of selfinterest. In line with the spirit of educating people for the country and serving the people, colleges and universities should deepen reform and innovate continuously to train qualified kindergarten teachers for the scientific development of teacher education.

\section{Conflicts of Interest}

The author declares no conflicts of interest regarding the publication of this paper.

\section{References}

[1] Du Y.W. (2018). British Teacher Education Partnership Model and Its Reference. Jiangxi Social Sciences, (9): 251.

[2] Lu J.Y. and Tao Q. (2018). Selection of Intern Instructors in the United States: Standards, Processes and Their Enlightenment --What Kind of Teacher can be a Teacher Educator. Foreign Elementary and Secondary Education, (3): 51.

[3] Hobson L.D. and Harris D. (2012). The Importance of Mentoring Novice and Pre-service Teachers: Findings from a HBCU Student Teaching Program. Educational Foundations, HBCU. 